\title{
The composition of the vapor phase upon evaporation of a mechanical mixture of cadmium and zinc selenotelluride powders
}

\author{
(C) Alexey P. Belyaev, ${ }^{1,2 *+}$ Vladimir V. Antipov, ${ }^{3}$ and Dmitry A. Mokhorov ${ }^{2}$ \\ ${ }^{1}$ Department of Phisical and Colloidal Chemistry. St. Petersburg State Chemical-Pharmaceutical \\ University. Professor Popov St., 14. St. Petersburg, 197376. Russia. \\ Phone: +7 (812) 499-3900, add.41-40. E-mail: Alexei.Belyaev@pharminnotech.com \\ ${ }^{2}$ Peter the Great St. Petersburg Polytechnic University. Polytechnicheskaya St., 29. St. Petersburg, 195251. \\ Russia.Phone:+79643525060.E-mail:lex@spbstu.ru \\ ${ }^{3}$ Department of Analytical Chemistry. St Petersburg State Institute of Technology (Technical University). \\ Moscovsky Ave., 26. Saint-Petersburg, 190013. Russia. Phone: +7 (812) 494-93-71. \\ E-mail:vladimir@mail.ru
}

\begin{abstract}
*Supervising author; ${ }^{+}$Corresponding author
Keywords: vapor phase, vacuum sublimation, compounds A2B6, diffusion mixing of vapor.
\end{abstract}

\section{Abstract}

The effect temperature has on the composition of a vapor phase passed through a thermal field after the evaporation of a mechanical mixture of the powders of cadmium and zinc selenotelluride is studied. It is found that the composition of the vapor phase can be changed throughout the range of concentrations by varying the temperature. The results of the study are satisfactorily explained by the effect temperature has on the particle distribution function in correspondence to the weights of the molecules constituting the mixture.

There were virtually no molecules of the evaporated substance in the vapor phase, which consisted of diatomic molecules of the elements of Group VX compounds and metal atoms. This means that with the evaporation of mechanical mixtures of $C d T e$ and $C d S e$ powders, the vapor phase in the evaporator contains only $\mathrm{Cd}, \mathrm{Se}_{2}$, and $\mathrm{Te}_{2}$ molecules, while mixtures of $\mathrm{ZnTe}$ and $\mathrm{ZnSe}$ powders contain $\mathrm{Zn}, \mathrm{Se}_{2}$ and $\mathrm{Te}_{2}$ molecules. Despite the similarity between the components' heats of sublimation, their concentrations over the powdermixture did not correspond to the composition of the powder mixture, since compounds A2B6 sublimate incongruently. Coming from the evaporator, the vapor phase entered the thermal field and was condensed onto a substrate at room temperature at its outlet. As follows from the composition of the substrate films, the vapor phase at the outlet was enriched with the light component $S e$, compared to the powder mixture. By virtue of the law of the conservation of mass, the vapor phase was therefore enriched with the heavy component $\mathrm{Te}$ at the inlet to the thermal field.

Our results show that the thermal field controls the composition of the vapor phase by changing the particle distribution function according to the weight of the molecules constituting the mixture.

The temperature dependences of the composition of the vapor phase are presented for several mechanical mixtures of the powders of $(\mathrm{CdSe})_{x}(\mathrm{CdTe})_{1-x}$ and $(\mathrm{ZnSe})_{x}(\mathrm{ZnTe})_{1-x}$, where $\mathrm{x}=0.45-0.90$.

\section{References}

[1] Technology of thin films. Under. ed. L. Meissela, R. Glanga. Moscow: "Soviet radio". 1977. 664p. (russian)

[2] A.P. Belyaev, V.P. Rubets, I.P. Kalinkin, M.Y. Nuzdin. Effects of ordering of an ensemble of dispersed particles in a weak field of elastic stresses of the substrate during condensation from the vapor phase under sharply nonequilibrium conditions. Russian Journal of Physical Chemistry A. 2003. Vol.77. No.10. P.1847-1852.

[3] A.P. Belyaev, V.P. Rubets, V.V. Antipov, E.O. Eremina. Nucleation of CdTe Islands during Synthesis from the Vapor Phase on a Cooled Substrate. Semiconductors. 2011. Vol.45. No.10. P.1297-1300.

[4] M. Grabau, H.-P. Steinrück, C. Papp. Physical vapor deposition of Ga on polycrystalline Au surfaces studied using X-ray photoelectron spectroscopy. Surface Science. 2018. Vol.677. No.11. P.254-257.

[5] P. Samaddar, Y.S. Ok, K.-H. Kim. Synthesis of nanomaterials from various wastes and their new age applications. Journal of Cleaner Production. 2018. Vol.197. No.10. P.1190-1205.

[6] A.P. Belyaev, V.P. Rubets, V.V. Antipov. Vertical growth of cadmium sulfide crystals on a silicon substrate. Russian Journal of Physical Chemistry A. 2017. Vol.91. P.342-345. 
THE COMPOSITION OF THE VAPOR PHASE UPON EVAPORATION OF A MECHANICAL MIXTURE...

[7] C. Liu, Z. Chen, N. Qian, Y. Ma. Tubular V-free and V-doped $\mathrm{TiO}_{2}$ derived from $\mathrm{H}_{2} \mathrm{Ti}_{12} \mathrm{O}_{25}$ hollow spheres: Vapour-thermal synthesis, morphology evolution, and photocatalytic performance. Ceramics International. 2018. Vol.44. No.11. P.19535-19542.

[8] J.H. Nam, M.J. Jang, H.Y. Jang, W. Park, X. Wang, S.M. Choi. Room-temperature sputtered electrocatalyst $\mathrm{WSe}_{2}$ nanomaterials for hydrogen evolution reaction. Journal of Energy Chemistry. 2020. Vol.47. No.8. P.107-111.

[9] P. Srinivasan, B.G. Jeyaprakash. Fabrication of highly selective formaldehyde sensor through a novel spray deposited $\mathrm{ZnO} / \mathrm{CdS}$ heterostructured interface: A surface charge enhancement approach. Journal of Alloys and Compounds. 2018. Vol.768. No.11. P.1016-1028.

[10] A.P. Belyaev, V.P. Rubets, V.V. Antipov, and N.S. Bordei. Formation of the Molecular Crystal Structure during the Vacuum Sublimation of Paracetamol. Russian Journal of Physical Chemistry A. 2015. Vol.89. No.4. P.575-580.

[11] P. Yang, Y. Zhang, P. Wang. Heat transfer measurement and flow regime visualization of two-phase pulsating flow in an evaporator. International Journal of Heat and Mass Transfer. 2018. Vol.127. No.12. P.1014-1024.

[12] A. Dittmar, J. Wollweber, M. Schmidbauer. Physical vapor transport growth of bulk $\mathrm{Al}_{1-\mathrm{x}} \mathrm{Sc}_{\mathrm{x}} \mathrm{N}$ single crystals. Journal of Crystal Growth. 2018. Vol.500. No.10. P.74-79.

[13] A.P. Belyaev, V.P. Rubets, and S.A. Belyaeva. Crystallization of cadmium telluride on single crystal substrates cooled with liquid nitrogen. Butlerov Communications. 2015. Vol.41. No.2. P.155-159. DOI: 10.37952/ROI-jbc-01/15-41-2-155

[14] E.Yu. Rodionova, I.B. Dmitrieva, and A.S. Chukhno. Influence of the dispersion medium composition on the stability and electrokinetic properties of bilirubin. Butlerov Communications. 2014. Vol.37. No.1. P.56-61. ROI: jbc-02/14-37-1-56

[15] A.P. Belyaev, V.P. Rubets, I.P. Kalinkin. Optical Absorption Edge and Modification Due the Decomposition on Cadmium Telluride and Cadmium Sulfide Solid Solution Films. Semiconductors. 1997. Vol.31. No.5. P.540-542.

[16] A.P. Belyaev, V.P. Rubets, I.P. Kalinkin. Conductivity Stimulated by Temperature Oscillations in Dissociated Cadmium Telluride and Cadmium Sulfide Solid Solutions. Semiconductors. 1997. Vol.31. No.8. P. 823-825.

[17] A.P. Belyaev, V.P. Rubets, V.V. Antipov, A.O. Ribnikov, and S.A. Belyaeva. Crystallization of paracetamol of rhombic form. Butlerov Communications. 2014. Vol.37. No.3. P.113-119. ROI: jbc02/14-37-3-113

[18] A.P. Belyaev, V.P. Rubets, V.V. Antipov, N.S. Bordei. Phase Transformations during the Growth of Paracetamol Crystals from the Vapor Phase Technical Physics. 2014. Vol.84. No.7. P.1101-1103.

[19] A.P. Belyaeva, V.V. Antipov, V.P. Rubets. Formation of Cadmium-Sulfide Nanowhiskers via Vacuum Evaporation and Condensation in a Quasi-Closed Volume. Semiconductors. 2016. Vol.50. No.3. P.415-417.

[20] A.P. Belyaev, V.P. Rubets, V.V. Antipov. Vertical Growth of Cadmium Sulfide Crystals on a Silicon Substrate. Russian Journal of Physical Chemistry A. 2017. Vol.91. No.2. P.342-345.

[21] A.P. Belyaev, V.P. Rubets, V.V. Antipov. Study of the Structure of Cadmium-Sulfide Nanowire Crystals Synthesized by Vacuum Evaporation and Condensation in a Quasi-Closed Volume. Semiconductors. 2018. Vol.52. No.1. P.118-119.

[22] A.P. Belyaev, V.P. Rubetz, and V.V. Antipov. Properties of filamentary nanocrystals of cadmium sulfide synthesized by vacuum evaporation and condensation. Butlerov Communications. 2019. Vol.57. No.1. P.149-153. DOI: 10.37952/ROI-jbc-01/19-57-1-149

[23] A.P. Belyaev, V.P. Rubets, V.V. Antipov. Distribution of Molecules in the Vapor Phase during Vacuum Evaporation of a Mechanical Mixture of Powders of Cadmium Selenide and Telluride. Russian Journal of Physical Chemistry A. 2019. Vol.93. No.9. P.1649-1651.

[24] A.P. Belyaev, V.P. Rubetz, V.V. Antipov and D.A. Mokhorov. Conductivity inversion in $\mathrm{CdSe}_{\mathrm{x}} \mathrm{Te}_{1-\mathrm{x}}$ solid solutions. Butlerov Communications. 2019. Vol.60. No.11. P.16-19. DOI: 10.37952/ROI-jbc01/19-60-11-16

[25] I.P. Kalinkin, V.B. Aleskovsky, A.V. Simashkevich. Epitaxial films of A2B6 compounds. Leningrad: $L S U$. 1978. 311p. (russian)

[26] E.M. Lifshits, L.P. Pitaevsky. Theoretical physics. Physical kinetics. Vol.X. Moscow: Fizmatlit. 2002. 536p. (russian)

[27] D.A. Frank-Kamenetskiy. Diffusion and heat transfer in chemical kinetics. 3rd ed. Moscow: Nauka. 1987. 504p. (russian)

[28] L.D. Landau, E.M. Lifshits. Theoretical physics. Statistical physics. Vol.V. Moscow: Nauka Fizmatlit. 1995. 608p. (russian) 